\title{
Psicologia do Trânsito: O Nascimento de Uma Ciência
}

\author{
Alessandra Sant'Anna Bianchi \\ Universidade Federal do Paraná
}

\begin{abstract}
RESUMO
A Assembleia Geral da Organização das Nações Unidas declarou a década 2011-2020 a "Década de Ação para Segurança Viária" com a meta de estabilizar e reduzir a mortalidade mundial prevista por acidentes de trânsito em 2020. Nessa tarefa, a psicologia do trânsito, com seu arcabouço de teorias e dados, não pode omitir-se, e mais, está sendo chamada a ser protagonista já que um dos cinco pilares para as ações da década 2011-2020 contempla justamente o comportamento humano. Este trabalho apresenta os primórdios da psicologia do trânsito possibilitando uma melhor compreensão dos rumos desta até os dias atuais. O período abarcado pelo trabalho é aquele compreendido entre 1866 e 1930 , quando a IV Conferência Internacional de Psicotécnica solicita aos poderes públicos a adoção da obrigatoriedade do exame psicológico para condutores.
\end{abstract}

Palavras-chave: transporte; mobilidade; segurança; trânsito; história.

\begin{abstract}
Traffic Psychology: The Birth of a Science

The General Assembly of the United Nations declared the 2011-2020 decade, the "Decade of Action for Road Safety" with the goal to stabilize and to reduce foreseen worldwide mortality in traffic accidents until 2020. In this task, traffic psychology, with its theories and data, cannot disregard such issue and is called to be a protagonist since human behavior is one of the five pillars of the planned actions for this decade. The present paper brings out the origins of traffic psychology allowing a better understanding of its trajectory until current days. The 1866-1930 period is studied in this paper, and the IV International Conference of Psychotechnics is highlighted as it requested from governments the mandatory adoption of the psychological examination for drivers.
\end{abstract}

Keywords: transportation; mobility; safety; traffic; history.

Em 2 de março de 2010 a Assembleia Geral da Organização das Nações Unidas declarou a década 20112020 a "Década de Ação para Segurança Viária" com a meta de estabilizar e reduzir a mortalidade mundial prevista por acidentes de trânsito em 2020 (Organização das Nações Unidas, 2010). A iniciativa de solicitar essa declaração à Organização das Nações Unidas foi da Primeira Conferência Ministerial Global sobre Segurança no Trânsito, realizada em Moscou em novembro de 2009 (First Global Ministerial Conference on Road Safety, 2009) frente aos dados desesperadores apresentados pela Organização Mundial da Saúde (2009) e que indicavam que morrem, por ano, mais de 1.200.000 pessoas vítimas de acidentes de trânsito. A versão preliminar do documento de planejamento (Organização Mundial da Saúde, 2010) se estrutura em cinco grandes pilares, sendo o quarto deles "Influenciar o comportamento dos usuários das vias".
Comportamento é o objeto de estudo da Psicologia (Davidoff, 2001) e trânsito a especificidade da Psicologia do Trânsito. Este trabalho apresenta a psicologia do trânsito desde os seus primórdios possibilitando uma melhor compreensão dos rumos desta até os dias atuais. Estudar a história de uma ciência, ou parte dela, é sempre uma tarefa com amplas ramificações, porque para entender uma ciência em particular é necessário conhecer também seu contexto histórico, e costuma ser este emaranhado de datas e fatos o que ajuda a dar sentido àquela. $\mathrm{O}$ período abarcado pelo trabalho é aquele compreendido entre 1866 e 1930, quando a IV Conferência Internacional de Psicotécnica solicita aos poderes públicos a adoção da obrigatoriedade do exame psicológico para condutores.

O fenômeno da condução humana de veículos automotores tem seu início no ano 1866 com a fabricação do primeiro automóvel movido a motor pela empresa Daimler, na Alemanha. Começa então uma pre- 
ocupação pelas atitudes necessárias para manejar esta nova máquina de forma que já no ano de 1880 são exigidos exames de aptidão para os condutores, especialmente dos profissionais do volante (Soler \& Tortosa, 1987).

É o médico italiano L. Patrizi quem por primeira vez, no ano de 1900, chama a atenção sobre a utilidade da psicologia para os problemas de trânsito indicando a necessidade de examinar psicologicamente os condutores de automóveis, controlando fundamentalmente a "constância de sua atenção" (Dorsch, 1963). O primeiro Código de Trânsito para automóveis foi criado na Alemanha em 1901 (Landesregierung Provinz Schleswig-Holstein, 1903) contando em sua elaboração com a contribuição dos primeiros expertos que foram encarregados do exame de condutores de automóveis em Hamburgo (1902), Hannover (1903) e Essen (1904). Nele, se fixam as condições físicas, sensoriais, caracteriológicas e éticas para obter a permissão para conduzir e dela fazer uso (Germain, 1966).

Em 1910, Münsterberg criou, no laboratório de psicologia de Harvard (Estados Unidos), por solicitação da American Association for Labor Legislation, o primeiro teste de aptidão para condutores. O teste buscava avaliar condutores candidatos ao trabalho em suas respostas a situações de trânsito que iam mudando e eram apresentadas em uma fita de papel móvel (Bringmann, Lück, Miller, \& Early, 1997). Münsterberg (1914) iniciou com provas que simulavam, em um micro sistema, a atividade de condução, mas logo muda a sistemática de provas passando a avaliar a analogia interna da situação mental do trabalhador.

Em 1915 muitos países estabeleceram a obrigatoriedade de um exame psicotécnico de aptidão para a condução aos motoristas profissionais de veículos de serviço público ou de transportes coletivos, os maquinistas de ferrocarril, os condutores de bondes e os taxistas (Caparros, 1985). Segundo Dorsch (1963), a primeira divergência sobre metodologia na área pode ser assinalada como a protagonizada por G. Gerhardt e V. Viteles que, à diferença de H. Münstenberg, defendiam a conveniência de que os exames de condução acontecessem mediante modelos miniatura que simulassem as situações externas dos condutores.

No campo da pesquisa, na Europa a tendência geral é examinar a conduta específica da condução em situações afins às autênticas. Especialmente destacáveis foram as pesquisas feitas na Alemanha e na França. Na Alemanha, os grandes pioneiros Moede e
Piorkowski (1919), construíram e aperfeiçoaram os primeiros simuladores de condução. $\mathrm{O}$ procedimento que estes autores elaboraram considera-se como o primeiro exame médico-psicológico de aptidão do condutor. Também na área de elaboração de instrumentos para a avaliação de condutores, é importante destacar o trabalho de Rupp (1916) e de Lahy (1918). Rupp (1916) melhorou os procedimentos de Munstenberg e ideou um aparato que se converteu em muito popular, um volante mediante o qual o candidato tinha que seguir uma linha traçada sobre uma fita corrediça na que se havia simulado um terreno viário. Lahy (1918) desenvolveu dispositivos cinematográficos que permitiam examinar as reações dos sujeitos frente a situações viárias de distinta índole.

Em 1918, com a crescente incorporação das mulheres à atividade de condução, Stern (1918) criou, na Alemanha, o primeiro teste psicotécnico específico para mulheres condutoras. Este teste marca a primeira aceitação das diferenças de gênero na atividade de condução, que até os dias de hoje são ponto de investigação (Begg, Langley, \& Williams, 1999; Katila \& Keskinen, 2000; Monteiro \& Günther, 2006).

Segundo Germain (1966), dois fatores facilitaram o desenvolvimento que experimentou esta área de pesquisa depois da Primeira Guerra Mundial. O primeiro fator é que a guerra obrigou os exércitos dos países beligerantes a seleções psicotécnicas a grande escala e a elaboração de provas e instrumentos. O segundo fator foi o crescimento dos Laboratórios de Psicologia Experimental, cujas atividades práticas começaram a desenvolver-se, provendo assim aos psicólogos meios úteis para a exploração das atitudes que se julgavam mais importantes nos condutores.

A primeira reunião sobre transporte e psicologia foi realizada em 1920, em Genebra, no âmbito da psicometria, como resultado de questões práticas sobre a seleção de condutores profissionais em todos os tipos de transporte (Montoro, Carbonell, \& Tortosa, 1991). Em 1921, Barcelona foi sede da Segunda Conferência Internacional de Psicotécnica presidida por Claparede. Entre os assistentes se encontravam importantes figuras da psicologia européia como Mira y López, Lahy, Burt, Piorkowski, Moede e Madariaga. Esta conferência teve um importante efeito prático ao abrir para os psicólogos o campo de trabalho da seleção de condutores de veículos mecânicos. Em efeito, um dos principais acordos foi solicitar aos governos a obrigatoriedade de um exame psicotécnico para a seleção dos condutores: "Fica aprovado que nos serviços de transporte (ferrocarris, bondes, automóveis, 
navegação) o contrato de trabalho não se faça sem um exame psicofisiológico prévio das atitudes profissionais e outro psiquiátrico" (Instituto de Orientación y Selección Profesional de Barcelona, 1921). A Conferência recomendou também um controle posterior médico-psicológico que deveria ser renovado periodicamente.

O efeito desta recomendação se fez sentir na Espanha já no ano de 1922, quando a Prefeitura de Barcelona exigiu da Companhia Geral de Ônibus de Barcelona que seus condutores obtivessem um certificado de aptidão profissional por meio de um exame psicofisiológico prévio e gratuito (Carpintero, 1994; Kirchner, 1981). Dadas as limitações econômicas do Centro onde estes exames deviam realizar-se, seu diretor, Mira i López, elaborou um conjunto de provas psicotécnicas capazes de avaliar aptidões profissionais segundo as exigências psicológicas estabelecidas no profissiograma do condutor.

$\mathrm{Na}$ França, o uso dos testes psicométricos no transporte público foi iniciado por Lahy e Guyot (Lahy, 1918) e apresentou resultados, já no mesmo ano, de um decremento na taxa anual de acidentes por condutor. Em 1925, os condutores de trens começaram a ser avaliados por meio de testes psicológicos em Budapeste, seguidos pelos de Bucareste em 1926 (Barjonet, 1997).

Nesta mesma época (anos 20), nos Estados Unidos, ao não haver uma estrita seleção no processo para conceder um documento de permissão de condutores, impedir a determinadas pessoas de voltar a conduzir era o principal trabalho da psicologia para promover segurança no trânsito entre condutores não comerciais; esta tarefa de remover condutores se ajustava no trabalho da psicologia forense (Albert, 1999).

$\mathrm{Na}$ Espanha, as pesquisas, no Instituto de Madri, sobre as aplicações da psicologia à condução começam a dar frutos em 1925. Nas "Memórias do Instituto de Reeducação Profissional de Inválidos do Trabalho" daquele ano, indica-se que um dos principais trabalhos de pesquisa do centro é o estudo e o desenvolvimento de instrumentos e provas para a seleção de condutores de veículos, especialmente de condutores profissionais (Instituto de Reeducação Profissional de Inválidos do Trabalho, 1925). Neste mesmo ano, e dentro desta linha de investigação, cabe destacar o perceptotaquímetro universal óptico, criado por Madariaga, e que se converteu em peça chave do exame psicotécnico de aptidão para a condução realizado no Instituto de Madri. Os Institutos de Madri e Barcelona compartilhavam princípios, fins e métodos, já que partiam de um professiograma similar e da consideração da condução como uma profissão reativa.

$\mathrm{Na}$ Espanha, a finais dos anos vinte e início dos trinta do século passado, se produziu um grande aumento no número de testagens psicotécnicas para a seleção de condutores. Empresas, como a petrolífera transportes S.A., começaram a contratar os serviços de seleção psicológica de seu pessoal condutor em 1929 (Mallart, 1974). Também instituições públicas passaram a solicitar os serviços de exame psicotécnico para seus condutores como o Ministério de Obras Públicas em 1929, que encarrega a seleção psicotécnica de motoristas vigilantes de rodovias, e as forças armadas, para a seleção dos aspirantes a ingresso na Escola de Automobilismo do Exército em 1930.

Assim, em 1930 Barcelona tornou-se sede da VI Conferência Internacional de Psicotécnica. A reunião foi organizada pelo Instituto de Barcelona e teve Claparede como presidente de honra. Compareceram personalidades de todo o mundo como Lahy, Gemelli, Lippmann, Bauer e Rupp, além de pesquisadores espanhóis como, por exemplo, Germain, Madariaga e Mira i López. Na sessão de encerramento foi aprovada a seguinte resolução:

Tendo em conta o perigo que encerra entregar a permissão de conduzir a indivíduos mal predispostos para a condução de mecanismos de transporte, a Conferência pede aos poderes públicos de todos os países que editem as medidas necessárias para que todo o pessoal condutor das empresas de transporte, tanto por terra, como por água e ar, seja submetido à seleção previa de aptidão por meio de exame psicotécnico (Instituto de Orientación y Selección Profesional de Barcelona, 1930).

Esse panorama de nascimento da psicologia do trânsito, fortemente correlacionada com a avaliação de condutores modificou-se ao longo dos anos. Nos anos 80, Rozestraten (1985) enviou questionários a instituições vinculadas ao estudo do trânsito em diversos países. Inglaterra, França, Bélgica, Alemanha Ocidental, Suíça, Finlândia, Áustria e Canadá responderam que a permissão para conduzir não estava condicionada a um exame psicológico. As razões apontadas para a ausência de utilização dos testes psicológicos como condição geral para a obtenção da permissão para conduzir foram as falhas na validez dos testes e o respeito pelo direito a privacidade de cada individuo quanto a seu psiquismo. O exame psicológico era realizado quando o exame médico deixava dúvidas quanto à capacidade psíquica do candidato, quando houvesse antecedentes criminais e quando os sujeitos 
tivessem se envolvido (frequentemente) em acidentes (graves) ou infrações (graves) de trânsito (Rozestraten, 1985).

Ao longo dos anos a psicologia do trânsito cresceu, principalmente na direção de constituir-se, mundialmente, como área de pesquisa e aplicação para compreensão de comportamentos e prevenção de acidentes. Modelos teóricos específicos foram desenvolvidos (Fuller, 2008; Näätänen \& Summala, 1974, 1976; Wilde, 1982, 1994) ainda que a área continue sendo essencialmente empírica e tome emprestadas das outras áreas da psicologia teorias que expliquem seus achados. Atualmente, a avaliação de condutores, tão importante nos primórdios dessa ciência, foi praticamente abandonada nos países europeus, onde ela foi acolhida após seu nascimento, exceção feita a Espanha (Monterde, 2009).

No Brasil de 2010, em que as estatísticas oficiais indicam mais de 35.000 mortos anuais em acidentes de trânsito (Brasil, 2009), é importante recordar que o estudo da história mostra a importância da integração entre pesquisadores e práticos da área para o desenvolvimento da ciência. A avaliação psicológica para obtenção da Carteira Nacional de Habilitação ainda é a mais concorrida atividade desenvolvida pelos psicólogos do trânsito no Brasil, mas a pesquisa floresce em alguns grupos e desde 2009 há um mestrado em psicologia, na Universidade Federal do Paraná, com uma linha específica de pesquisa na área. Urge unir esforços para que o fator humano, indicado como o grande vilão dos acidentes de trânsito (Montoro, Alonso, Esteban, \& Toledo, 2000) possa ser estudado e intervenções sejam desenvolvidas e implementadas com o objetivo de diminuir a acidentalidade viária. Nessa tarefa, a psicologia do trânsito, com seu arcabouço de teorias e dados não pode omitir-se, e mais, está sendo chamada a ser protagonista já que um dos cinco pilares para as ações da década 2011-2020 (Organização Mundial da Saúde, 2010) contempla justamente o comportamento humano.

\section{REFERÊNCIAS}

Albert, D. M. (1999). Psychotechnology and insanity at the wheel. Journal of the History of the Behavioral Sciences, 35, 291-305.

Barjonet, P. (1997). Transport psychology and transport in $\mathrm{Eu}-$ rope: A general overview. Em T. Rothengatter \& E. Carbonell (Orgs.), Traffic and transport psychology: Theory and application (pp. 21-30). Amsterdam: Pergamon.

Begg, D. J., Langley, J. D., \& Williams, S. M. (1999). A longitudinal study of lifestyle factors as predictors of injuries and crashes among young adults. Accident Analysis \& Prevention, 31, 1-11.

Brasil (2009). Saúde Brasil 2007: Uma análise da situação de saúde. Retirado em 3 de janeiro de 2010, de http://new. paho.org/bragc/index.php?option=com_docman\&task

Bringmann, W. G., Lück, H. E., Miller, R., \& Early, C. E. (Orgs.). (1997). A pictorial history of psychology. Chicago: Quintessence.

Caparros, A. (1985). Aspectos históricos de la psicología aplicada a la conducción. Em Dirección General de Tráfico (Org.), Primera Reunión Internacional de Psicología de Tráfico y Seguridad Vial (pp. 39-67). Madri: Dirección General de Tráfico.

Carpintero, H. (1994). Historia de la psicología en España. Madri: Eudema.

Davidoff, L. (2001). Introdução à psicologia (L. Peres, Trad.). São Paulo: Makron Books.

Dorsch, F. (1963). Geschichte und probleme der angewandten psychologie. Berna: Huber

First Global Ministerial Conference on Road Safety (2009). Moscow declaration. Retirado em 15 de dezembro de 2009, de http://www.who.int/roadsafety/ministerial_conference/declarati on_en.pdf

Fuller, R. (2008). What drives the driver? Surface tensions and hidden consensus. Retirado em 20 de novembro de 2009, de www.icttp.com

Germain, J. (1966). El psicólogo y la seguridad vial. Revista de Psicología General y Aplicada, 21, 893-934.

Instituto de Orientación y Selección Profesional de Barcelona (1921). Actas de la II Conferencia de Psicotecnia. Barcelona: Instituto de Orientación y Selección Profesional de Barcelona.

Instituto de Orientación y Selección Profesional de Barcelona (1930). Actas de la VI Conferencia Internacional de Psicotecnia. Barcelona: Instituto de Orientación y Selección Profesional de Barcelona.

Instituto de Reeducación Profesional de Inválidos del Trabajo (1925). Memorias del Instituto de Reeducación Profesional de Inválidos del Trabajo. Madri: Instituto de Reeducación Profesional de Inválidos del Trabajo.

Katila, A., \& Keskinen, E. (2000, setembro). The speed factor in fatal road traffic accidents. Trabalho apresentado na International Conference on Traffic and Transport Psychology 2000, Berna.

Kirchner, M. (1981). La obra de Emilio Mira en el Instituto de Orientación Profesional de Barcelona (1919-1939). Revista de Historia de la Psicología, 2, 225-246.

Lahy, J. M. (1918). Gründung der vereinigung für internationale psychotechnische konferenzen. Industrielle Psychotechnik, 11, 349-350.

Landesregierung Provinz Schleswig-Holstein (1903). Polizeiverordnung über den Verkehr mit Kraftfahrzeugen. Landesarchiv Berlin X Jahrg. Deutsche Juristen-Zeitung, 18, 855-856.

Mallart, J. (1974). Cincuentenario del originalmente llamado Instituto de Orientación y Selección Profesional. Revista de Psicología General y Aplicada, 29, 929-930.

Moede, W., \& Piorkowski, C. (1919). Editorial. Praktische Psychologie, 1, 1-2. 
Monteiro, C. A. S., \& Günther, H. (2006). Agressividade, raiva e comportamento de motorista. Psicologia: Pesquisa \& Trânsito, 2, 9-17.

Monterde, H. B. (2009). O modelo de avaliação médicopsicológica: Desenvolvimento atual e críticas. Em A. S. Bianchi (Org.), Humanidade e trânsito: Desafios para um futuro sustentável. Curitiba: Conselho Regional de Psicologia do Paraná.

Montoro, L., Alonso, F., Esteban, C., \& Toledo, F. (2000). Manual de seguridad vial: El factor humano. Barcelona: ArielIntras.

Montoro, L., Carbonell, E., \& Tortosa, F. (1991). Psicología y seguridad vial en España: 70 años de historia. Revista de Historia de la Psicología, 12, 73-86.

Münsterberg, H. (1914). Grundzüge der psychotechnik: Psychologie für die lösung der probleme der modernen welt der industrie, des verkehrs und des rechts. Leipzig: Barth.

Näätänen, R., \& Summala, H. (1974). A model for the role of motivational factors in driver's decision-making. Accident Analysis \& Prevention, 6, 243-261.

Näätänen, R., \& Summala, H. (1976). Road-user behaviour and traffic accidents. Amsterdam: North-Holland.

Organização das Nações Unidas (2010). Resolução da assembléia geral das Nações Unidas A/64/L.44. Retirado em 2 de março de 2010, de http://daccess-dds-ny.un.org/doc/UNDOC/LTD/ N10/251/13/PDF/N1025113.pdf?OpenElement
Organização Mundial da Saúde (2009). Global status report on road safety: Time for action. Retirado em 27 de novembro de 2009, de http://www.who.int/violence_injury_prevention/road_ safety_status/2009

Organização Mundial da Saúde (2010). A decade of action for road safety: A brief planning document. Retirado em 2 de março de 2010, de http://www.who.int/roadsafety/decade_of_action.pdf

Rozestraten, R. J. A. (1985). O exame psicológico para motorista em alguns países fora do Brasil. Psicologia \& Trânsito, 2, $67-$ 74.

Rupp, H. (1916). Grundsätzliches über eignungsprüfungen. Zeitschrift für Angewandte Psychologie, 29, 32-62.

Soler, J., \& Tortosa, F. (1987). Psicología y seguridad vial en España: Una perspectiva histórica. Valencia: Nau Livros.

Stern, W. (1918). Über psychologie der individuellen differenzen: Ideen zu einer "differentiellen psychologie". Schriften der Gesellschaft für Psychologische Forschung, 12, 5-12.

Wilde, G. (1982). The theory of risk homeostasis: Implications for safety and health. Risk Analysis, 2, 209-225.

Wilde, G. (1994). Risk homeostasis theory and its promise for improved safety. Em R. M. Trimpop \& G. Wilde (Orgs.), Challenges to accident prevention: The issue of risk compensation processes (pp. 9-24). Groningen: Styx.

\section{Sobre a autora:}

Alessandra Sant'Anna Bianchi - Psicóloga, Mestre em Psicologia do Desenvolvimento pela Universidade Federal do Rio Grande do Sul, Doutora em Psicologia pela Universidad de Barcelona. Professora adjunta do Departamento de Psicologia da Universidade Fe deral do Paraná.

Esse trabalho recebeu financiamento do $\mathrm{CNPq}$

Endereço eletrônico: bianchi@ufpr.br 